\title{
Authors' reply to the comment by Hanis et al. on "Predictors of unsuccessful pessary fitting in women with prolapse: a cross-sectional study in general practice," by Panman et al.
}

\author{
Janny H. Dekker ${ }^{1}$ (D) $\cdot$ Huibert Burger $^{1}$
}

Received: 12 June 2017 / Accepted: 29 June 2017 / Published online: 26 July 2017

(C) The International Urogynecological Association 2017

\section{Dear Editor,}

Thank you very much for giving us the opportunity to respond to the comment of Hani et al. on some methodological aspects of our study on the success of fitting a pessary in women in primary care.

The first comment by Hanis et al. is on the cross-sectional design of our study, which would make it difficult to draw conclusions on the predictors of fitting success, as this would require a longitudinal study. We do not agree with this comment: In a cross-sectional study, it is possible to study diagnostic predictors, with the diagnosis in our study being unsuccessful pessary fitting [1]. We agree that no causal inferences should be made in prediction studies (diagnostic and prognostic). That is why we stated in our conclusions: "Our results indicated that lower age, higher BMI, and underactive or inactive pelvic floor muscle function were associated with a higher risk of unsuccessful pessary fitting."

In their second comment, Hanis et al. argue that considering the variables age, BMI, and pelvic floor muscle function as independent predictors is an optimistic interpretation. It will be clear from our response on the first comment that we indeed were very careful in interpreting the associations we found in our cross-sectional study. We agree that bootstrapping or other methods of internal validation are valuable techniques to correct a model for so-called overoptimism. This is particularly important when it is intended that the model is applicable directly to patients in clinical practice. In our study, however, the aim was more modest, i.e., to generate hypotheses about what the independent predictive factors are, as stated in the Discussion section. Given our sample size, construction of a final model was beyond our scope. We concluded that 'further research is needed to confirm the associations we found, and prediction models must be validated in other primary care populations," which is external validation. We thank the authors for emphasizing once again which methodological considerations should play a role in developing prediction models.

\section{Reference}

1. Moons KG, Altman DG, Reitsma JB, Ioannidis JP, Macaskill P, Steyerberg EW, et al. Transparent reporting of a multivariable prediction model for individual prognosis or diagnosis (TRIPOD): explanation and elaboration. Ann Intern Med. 2015;162(1):W1-W73.

This reply refers to the comment available at doi:10.1007/s00192-0173359-7.

Janny H. Dekker

j.h.dekker@umcg.nl

1 Department of General Practice, University Medical Center Groningen, University of Groningen, P.O. Box 196, 9700 AD Groningen, The Netherlands 